\title{
World Studio: a pedagogical experience using shape grammars and parametric approaches to design in the context of informal settlements
}

\author{
Fernando T. Lima \\ Pennsylvania State University | United States | fk15090@psu.edu \\ Universidade Federal de Juiz de Fora | Brazil | fernando.lima@arquitetura.uff.br \\ Naveen K. Muthumanickam \\ Pennsylvania State University | United States | nxm78@psu.edu \\ Marc L. Miller \\ Pennsylvania State University | United States | mlm693@psu.edu \\ José P. Duarte \\ Pennsylvania State University | United States | jxp400@psu.edu
}

\begin{abstract}
The World is experiencing a rapid surge in urban population, in addition to fast urbanization processes. Contemporary cities witness the rise of numerous urban and social problems, leading to the emergence of informal settlements. Still, computational and parametric resources have increasingly been adopted in novel approaches to urban planning and design. These resources can be used in informal settlements to improve urban quality without losing their essential features. This paper describes a teaching experience in the context of a design studio that uses shape grammars and parametric tools to design for an informal settlement context in Ahmedabad, India.
\end{abstract}

Keywords: Shape grammars; Parametrization; Informal settlements; Urban design; Teaching experience.

\section{INTRODUCTION}

The World is experiencing a rapid surge in urban population, in addition to fast urbanization processes, particularly in developing countries, such as Brazil and India. In this context, contemporary cities are witnessing the rise of numerous urban and social problems when the formal sector cannot provide adequate housing for this growing population, leading to the emergence of informal settlements. According to the United Nations (2020), one billion people live in informal settlements and slums worldwide, and an estimated population of 3 billion people will require adequate and affordable housing by 2030 .

On the other hand, computational and parametric resources have increasingly been adopted to develop novel approaches to urban planning and design (Lima et al. 2019). Verniz and Duarte (2020), for instance, have shown that such resources can be used to identify and reinterpret built patterns in informal settlements and to improve urban quality without losing their essential features - spatial diversity and cultural adequacy, to name a few.

Thus, this work aims to discuss the pros and cons of introducing shape grammars and parametric tools in a teaching approach for designing in the context of informal settlements. To this end, we present and discuss the results and the students' perceptions of a teaching experience related to a design studio that deals with shape grammars and parametric design to decode, encode, and recode urban patterns in an informal settlement in Ahmedabad, India. The studio's goal was to provide students with the ability to understand how cultural aspects shape the environment and how they can hack this process to develop new approaches to residential urban areas with improved quality of life. Results show that: i) the students believed that the studio had improved their computational skills - although a few recognized some difficulty in assimilating software content; ii) the students stated that the course had improved their abilities to understand and develop their design ideas; iii) the students were able to implement dynamic and flexible proposals that are sensitive to the cultural and social aspects they perceived during the site visit; iv) the studio contributed to increasing students' capacities for dealing with urban design as a whole (and more specifically with informal settlements).

This paper is structured into four sections: i) a brief review on shape grammars, parametric logic, and their use to tackle informal settlements; ii) a short report on the studio experience (the didactic approach, the site features, and the results of a survey given to students at the beginning and end of the studio); iii) a concise presentation and a discussion of the studio results (the students' proposals and their assessment of the course) and; vi) a discussion of the studio results and final remarks.

\section{SHAPE GRAMMARS, PARAMETRIZATION, AND INFORMAL SETTLEMENTS}

Stiny (1980) defines a shape grammar as "a set of shape transformation rules that apply recursively to an initial shape to generate a language of designs." Duarte and Beirão (2011) state that shape grammars can be implemented both in a descriptive or a generative manner to describe a corpus of existing designs, to explain how to 
generate new designs in the same language, and to create new languages of design.

The use of shape grammars in urban design is still limited when compared with architecture. However, previous works, such as those of Mayall and Hall (2005), Parish and Muller (2001), Duarte et al. (2007), and Duarte and Beirão (2011), for instance, have shown a growing interest in implementing shape grammars to deal with urban design problems. More recently, Verniz and Duarte's (2020) propose an analytical shape grammar for Santa Marta, an iconic informal settlement in Rio de Janeiro, Brazil.

Woodbury (2010) states that parametric modeling means to define the parameters for a complete or relevant specification of a model, requiring skills like data flow management, abstract thinking, mathematical logic manipulation, and algorithmic reasoning. In summary, parametrizing requires defining the parameters for a complete or relevant specification of a model or geometric object. Moreover, parametric logic introduces a fundamental modification to conventional modeling paradigms since it allows the parts of a given model to relate and change together in a coordinated manner.

The application of parametric resources to support urban design tasks has demonstrated a great potential to improve the generation, and the analysis of urban areas since the constituent components of a neighborhood or a slum also share similarities that can be captured into a parametric generative model. In addition, analytical attributes such as density, land use, and typology distribution - which typically belong to urban planning - can also be parametrically encoded. Therefore, it is possible to develop more effective and dynamic urban design processes and evaluate the pros and cons of different design scenarios in the quest for providing better and more affordable solutions for those currently living in informal settlements.

Implementing a parametric logic in urban design tasks means relating data, conditions, and variables, which implies thinking about the relationship between the various parts and the consequences of recomposing such relationships. Relating and recomposing mean fundamental changes in how computational resources are used in urban planning and design tasks. From this perspective, parametric models differ essentially from traditional digital modeling systems in that they allow the elaboration of flexible proposals. By changing one or more specific parameters, one can take advantage of a parametric model's capacity to continually generate and test different design alternatives within a controlled environment. However, as in shape grammars, the adoption of parametric urban design approaches is not as developed as in architecture. Nevertheless, the works of Steinø and Veirum (2005), Beirão (2012), Lima et al. (2017), Nourian et al. 2018, and Dogan et al. (2020), for instance, explore the use of parametric tools in the analysis and generation of urban areas. In this sequence, the work of Lima et al. (2019) presents a parametric approach to walkability, diversity, and density analysis in low-income neighborhoods in the city of Juiz de Fora, Brazil.

This paper extends these works by presenting a teaching experience, carried out in 2020, that explored the use of shape grammars, implemented in parametric design models to address the analysis and generation of proposals for a low-income settlement in the city of Ahmedabad, India.

\section{THE WORLD STUDIO EXPERIENCE}

Our studio experience took place at the Stuckeman College of Arts and Architecture, Pennsylvania State University. The course, entitled "World Studio 2020 - Ahmedabad", was attended by 21 architecture and landscape architecture students who were senior undergrad or master students and grouped into multidisciplinary teams. The course started in January and ended in May, with remote teaching adopted for desk crits and presentations in the second half of the studio due to the COVID-19 pandemic. As stated above, the main goal was to articulate shape grammars and parametric design in the development of alternatives to informal settlements seeking to provide students with an understanding of how to design affordable low-income residential areas with improved quality of life.

\section{THE TEACHING METHODOLOGY}

Our teaching methodology, adapted from Duarte and Beirão (2011), aim at providing students with a computational background for urban design, included six phases:

i) briefing - lectures, readings, and practical assignments on Pattern Language (Alexander et al., 1977) and Shape Grammars (Stiny, 1980; Duarte, 2005; Duarte \& Beirão, 2011; Verniz \& Duarte, 2020), as well as workshops on Rhino and Grasshopper;

ii) analysis - the identification of the main features of the intervention area and a reflection on the potential of the territory to sustain a vibrant and socially integrated urban community - that ended with a visit to the site and the city;

iii) strategy - the formulation of structured responses to site conditions, including the existing urban fabric (formal and informal) and the constitution of a vision to serve as the basis for the development of the proposed urban plans;

iv) conceptual design - the production of flexible urban plans following the proposed methodology, which included shape grammars and Grasshopper programming;

v) intermediate design - the development and refinement of the urban plans proposed in iv, and;

vi) detailed design - the presentation of the final plans, their rules, the explanation of how one could apply these rules, and a catalog of possible design configurations. Figure 1 summarizes the teaching approach and its phases. 


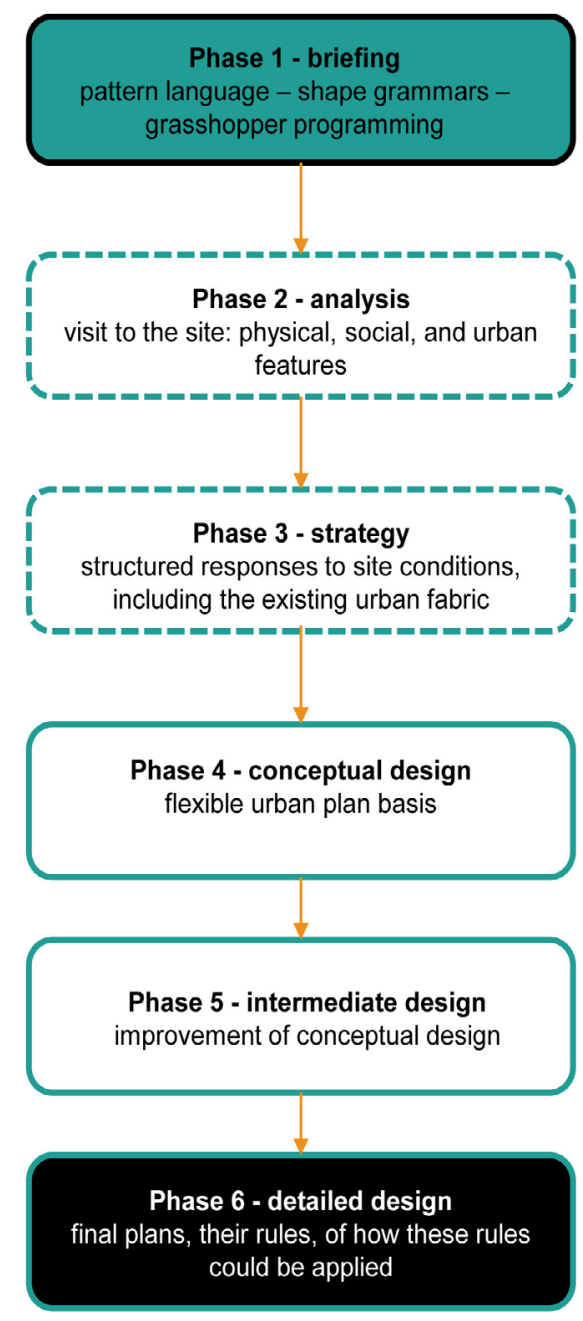

Figure 1: Diagram that summarizes our didactic approach.

\section{THE SITE FEATURES}

The studio focused on Ahmedabad, Gujarat's capital city in India. A major river, Sabarmati, geographically divides the city into eastern and western parts. The east bank of the river called the old walled city houses closely clustered buildings called pols, religious places of worship, and informal settlements called shawls. The western bank of the river, in turn, houses modern residential and institutional buildings along with shopping malls and business districts. Due to rapid industrialization and the recent smart city initiatives by the Government of India to develop Ahmedabad, there has been a recent surge in the densification of the city's formal and informal housing system. This has led to massive slum or shawl redevelopment projects by the Ahmedabad Municipal Corporation (AMC), aiming at relocating existing slums to better housing facilities, in situ renovation of informal settlements where relocation is not possible, and so on. These projects aim at providing better road networks, electricity, sanitation, sewage systems, and housing complexes meeting appropriate spatial standards (World Bank, 2007). The AMC has numerous initiatives to incorporate design suggestions and feedback from the local community through a participatory planning and design approach. However, these efforts still have knowledge gaps that need to be addressed. We utilized this studio to leverage technological solutions like advanced parametric design and computational tools to document, analyze, and synthesize various stakeholders' goals and desires, such as the residents, municipal council, designers, and builders. The idea was to encode these into a computational modeling system to design, analyze, and optimize a range of possible design interventions addressing the housing, public infrastructure, and landscape needs for Ahmedabad's specified site.

The members of the studio visited the site during Spring 2020. They held site surveys, discussions with local community groups and leaders to collect data and synthesize their needs and challenges. We collaborated with faculty and students of the Centre for Environmental Planning and Technology (CEPT), an accredited institution at Ahmedabad for GIS and the site's demographic data collection. We used this data to build sophisticated close to accurate models of the site conditions using Rhino, Grasshopper, and QGIS. Once we have developed the site conditions model, it was possible to analyze existing conditions such as pedestrian comfort and categorical density, spatial and construction qualities of existing building typologies.

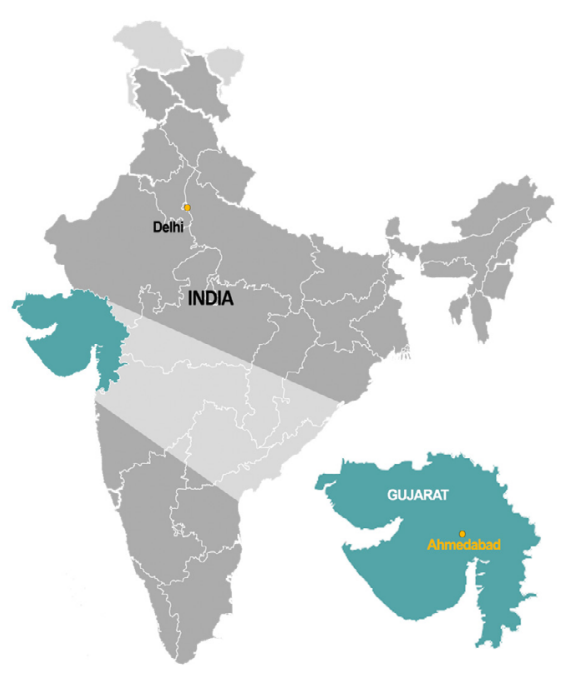

Figure 2: Ahmedabad location, in the state of Gujarat, India

The site visit provided the students with a set of cultural and socially meaningful information that they were able to identify personally, such as: i) the existing typologies and typical layout settings for living spaces; ii) the basic logic of local incremental built up practice; iii) some cultural, social and religious aspects, reflected on the arrangement of existing communities and; iv) the open and public space relation currently existing on site. Moreover, the students 
also identified the following existing issues: i) unhygienic conditions such as water contamination; ii) inadequate facilities for basic activities; iii) site flooding in monsoon season, and; iv) poor accessibility, among others.

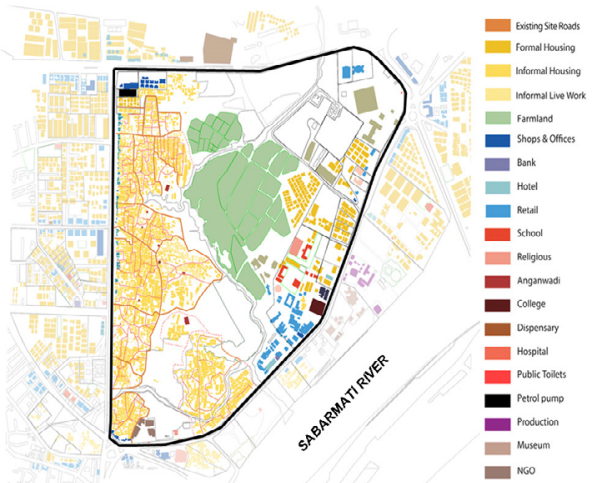

Figure 3: The intervention area (black outline), next to the Sabarmati river, and its current land use.

\section{THE STUDENTS SURVEY}

To assess the studio's contributions, we developed a survey in which we required students to describe their studio experience regarding: i) software skills (before and after the studio); ii) the use of parametric tools (Grasshopper + Rhinoceros) for the development of design ideas, and; iii) their willingness to use these tools again. Although the students worked in groups (six groups actually), they responded individually to the survey. The answers were given on a Likert scale ranging from 0 (meaning not at all) to 5 (meaning definitely yes). In some cases, respondents could provide additional information. Below is the list of the survey questions:

- Did you improve your modeling skills (in Rhino) during this studio?

- Did you improve your scripting skills (in Grasshopper) during this studio?

- Please rate your skill/expertise in handling Rhino - after the studio experience.

- Please rate your skill/expertise in handling Grasshopper - after the studio experience.

- How useful were parametric tools (Grasshopper w. Rhino) for developing your design? How helpful were parametric tools (Grasshopper w. Rhino) for developing multiple iterations of your design ideas?

- Which of the following 2D/3D modeling tools have you mostly worked with (during the studio)?

- In which aspects did parametric tools help you the most?

- Would you consider using parametric tools (Grasshopper + Rhinoceros) in the next design opportunity?

\section{RESULTS}

The studio results are presented under the following categories: i) student proposals - a brief commented description of the highlights of the six teams' designs, and ii) survey results - a description and analysis of the students' answers to the survey.

\section{STUDENTS' PROPOSALS}

Team 1's proposal consisted of a flexible design approach to generate both architectural and urban solutions. This meant designing and implementing parametric rules for the buildings, including dwellings and commercial spaces, urban blocks, and clusters. One of the main ideas was to improve pedestrian circulation by connecting the open spaces in the clusters. As a consequence of the hierarchic parametric definition involving the different scales, clusters were the result of the urban block's configuration, which, in turn, resulted from the design of the buildings, which was determined by the layout of the living units. Team 1's proposal (Figure 4) provided housing for 43000 people, almost doubling the existing population (22000).
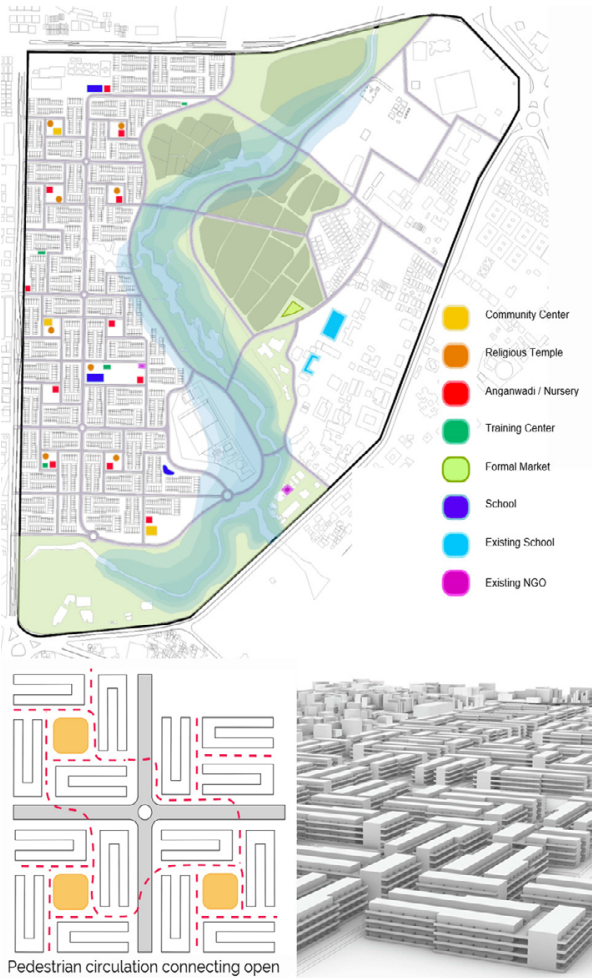

Pedestrian circulation con
spaces amongst clusters

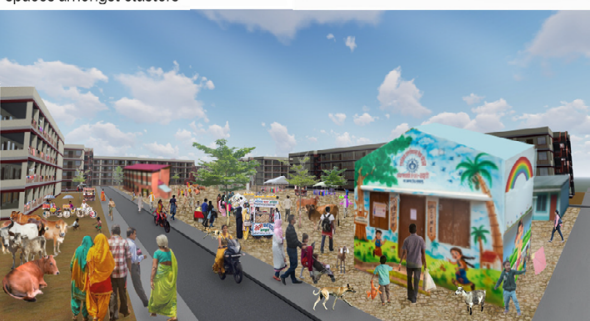

Figure 4: Team 1's masterplan, connecting parametrically defined clusters of four buildings (top and center) and a view of the proposed public space. Source: Group 1. 
Team 2's proposal (figure 5) explored a parametric approach to the generation of blocks and streets, based on rules defining a hierarchy of roads and open spaces. Their approach considered different rules for defining blocks shapes, aiming to contain various building typologies, and creating a gradual transition from high-rise (next to the street surrounding the terrain) to low-rise toward its center. In this sense, the group's idea was to provide different urban spaces to shelter different families and activities. The buildings were also parametrically defined, based on rules that constrained the layout of dwellings units and the buildings' shape. The group adopted a set of rules for linking the dwellings' layouts to a 3D grid structure, aiming to create a facade movement.
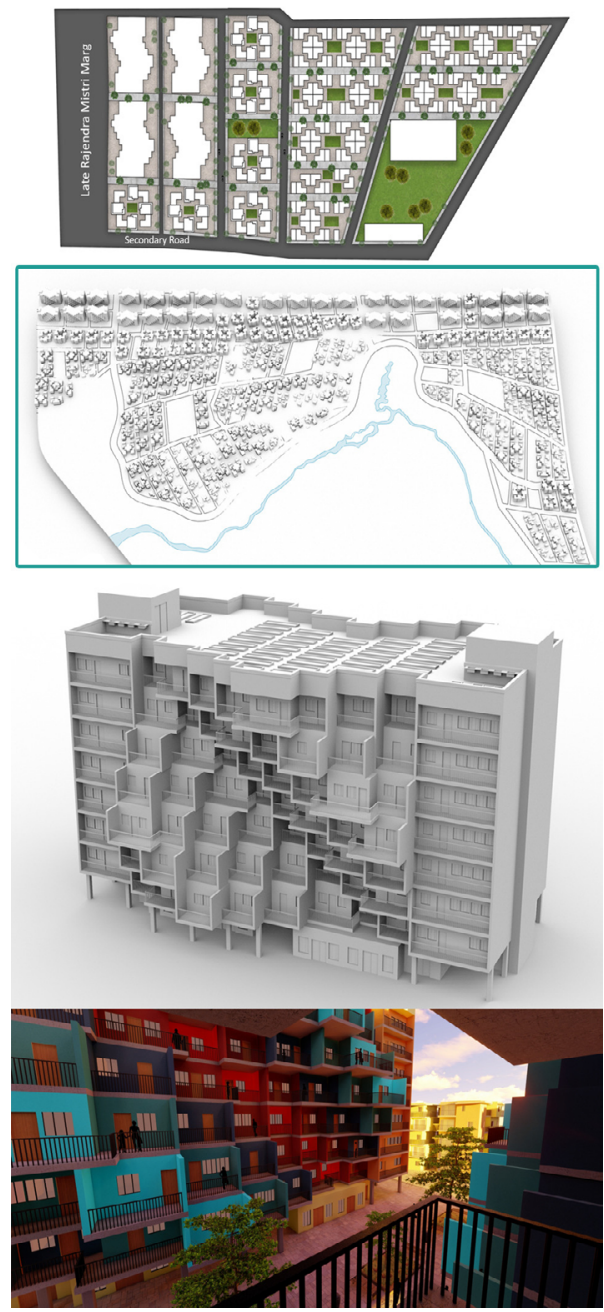

Figure 5: Team 2's proposal: different designs for blocks incorporating different building typologies and families (top). The group controlled the buildings' design parametrically, based on dynamic rules defined on an underlying grid (bottom).
Team 3's proposal (Figure 6) relied on two fundamental aspects: i) generation of streets and blocks supported by a set of rules that distributed green spaces and pocket parks, and ii) the possibility of increasing the area of the living units in a flexible, parametric way, allowing the living units to expand upon families' needs both along the $Z$ and in the $X$-axes. The aggregation and interaction between multiple typologies generated diverse spatial and formal configurations for the blocks, also controlled parametrically.

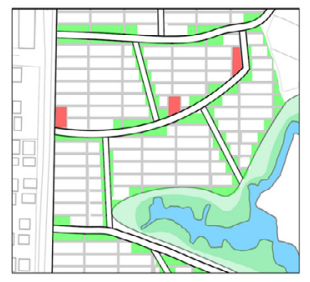

Greate green spaces and pocket parks along roads and at intersections when plots are not enough to become housing units
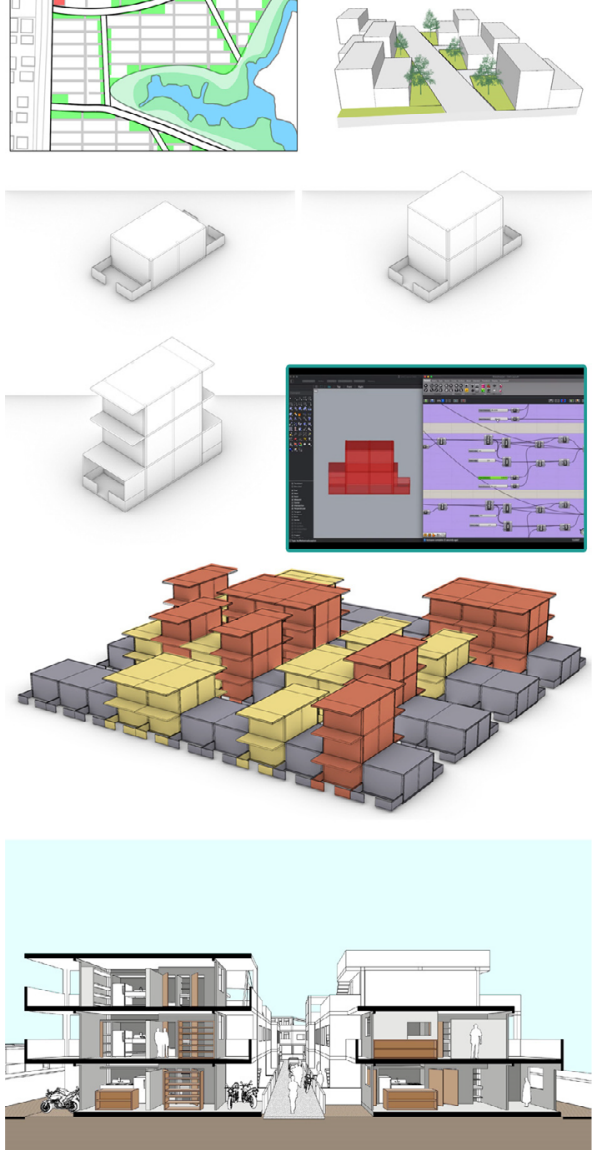

Figure 6: Team 3's proposal: providing pocket parks and green spaces (top) and allowing the housing units to expand, according to family needs (center and bottom).

Team 4 based their work on the idea of high-density lowrise apartments, pedestrian circulation, and the creation of dynamic and flexible gathering spaces. Therefore, their proposal for the site consisted of a strategy that addressed flexibility, a strong sense of community, "parametric road circulation," and "parametric urban clusters". Thus, a set of living units brings forth housing clusters organized in a pinwheel fashion, seeking to provide a fluid connection between the clusters and create flexible voids containing 
gathering spaces, temples, and markets, according to the different communities' needs, as shown in Figure 7. This proposal can shelter a total of approximately 85,950 residents.
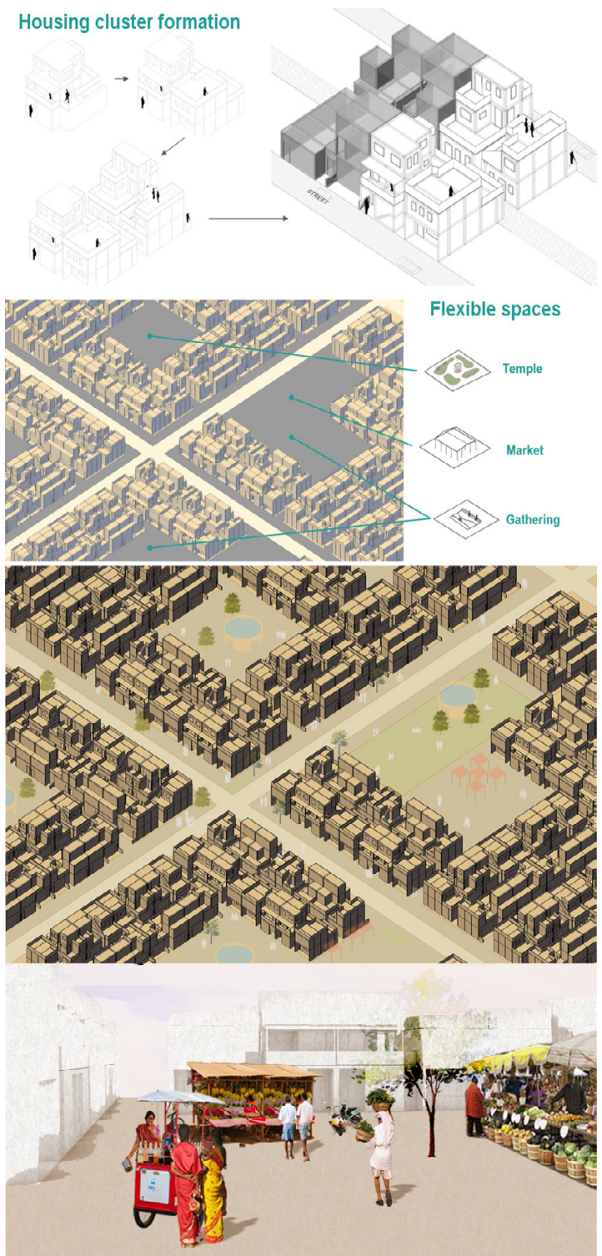

Figure 7: Team 4's idea of defining housing clusters (top) and organizing them in a pinwheel fashion (center) to promote circulation and creating dynamic gathering spaces (bottom).

Team 5 worked with the idea of a set of rules implemented parametrically to design customized living units and building configurations. The parameters controlling the dwellings' design and included: i) plot size; ii) stairs type and positioning; iii) the layout of kitchens and living areas; iv) the size and positioning of circulation spaces; v) the size and location of courtyards, and; vi) type and size of additions to rooms. Like other groups, this group implemented its rules in Grasshopper to quickly generate the dwelling units and the buildings, creating a diverse urban environment. Figure 8 shows the highlights of Team 5 's proposal.
Permanent Living + Typologies Rules
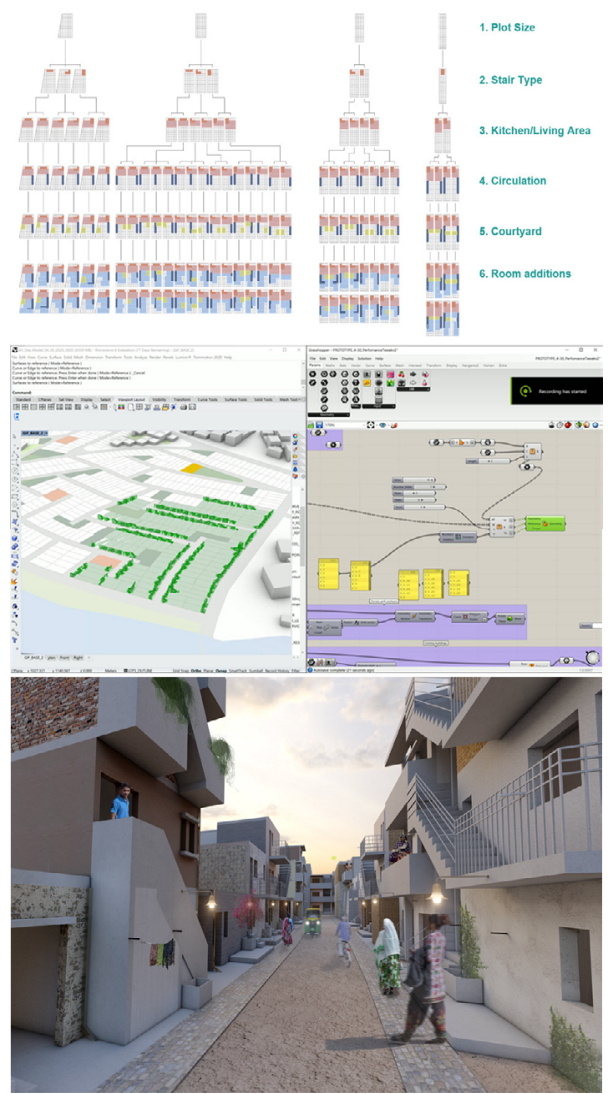

Figure 8: Team 5's rules for designing the living units (top) and generating the site arrangements (center) An image of the relation between the dwellings and the streets (bottom).

Team 6's work (Figure 9) dwelled on the notion of using urban design to empower women and children. Thus, they adopted the idea of organizing their urban blocks around community centers with facilities like daycares and schools, seeking to increase the accessibility to these amenities. Moreover, the group structured their proposal following three principles: i) keep lifestyles by referring to the existing communities; ii) preserve the natural stream and the nearby green area, taking advantage of these spaces to house leisure activities, and; iii) use the current access points to the site as references for planning new roads. These principles resulted in the following planning rules: i) parcel division - they used a Voronoi diagram to divide the site into ten communities and to determine the points with the shortest distance to each community's boundaries (Voronoi cells); ii) center location - the communities' center points provided the site for community centers and generated a "ring road", connecting all the communities centers; iii) community division - subdivide the communities into smaller areas and distribute the amenities among them; iv) parametrically subdivide the neighborhoods into plots. 

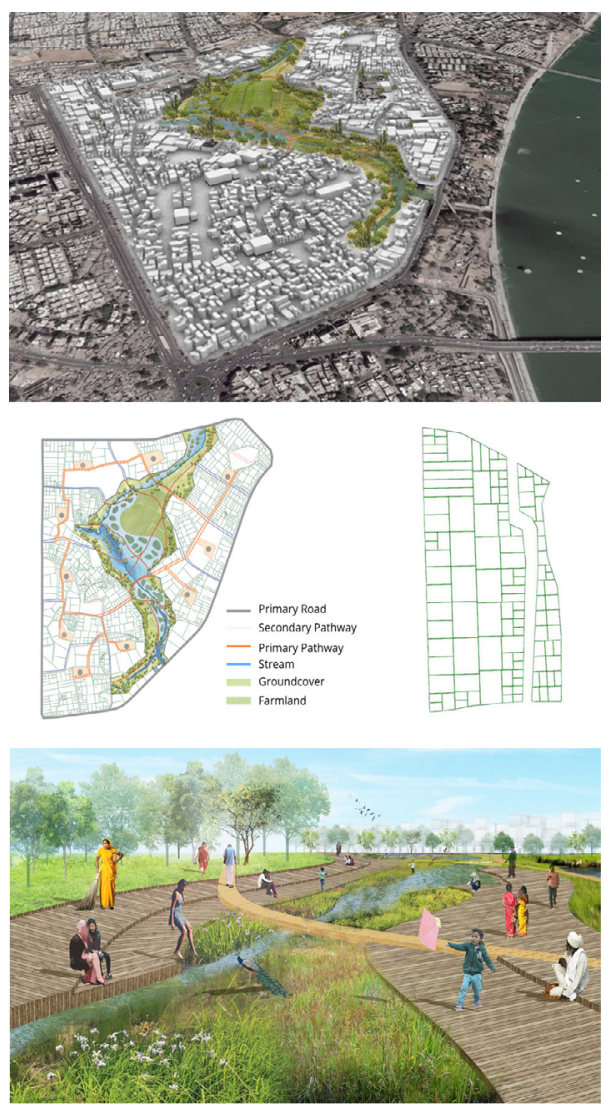

Figure 9: Team 6's proposal: bird's eye view (top), the logic for defining community centers and a "ring road" (center left), an example of parametrically driven plot division (center, right), and a view of their proposal for the nearby green area (bottom).

\section{SURVEY RESULTS}

The students' experience was essential to evaluate the adequacy and the effectiveness of the computational tools used to support the proposed didactic approach. 20 out of the 21 students enrolled in the studio answered the survey. The survey results show that: i) $75 \%$ of the students considered they improved their skills in Rhinoceros (grade 3 or higher); ii) $90 \%$ of the students believed they improved their skills in Grasshopper (grade 3 or higher); iii) $90 \%$ of the students considered that their skills in Rhinoceros, after the studio, went from good to excellent (grade 3 or higher); iv) $65 \%$ of the students considered that their skills in Grasshopper, after the studio, went from good to excellent (grade 3 or higher); v) $95 \%$ of the students consider that using Rhinoceros and Grasshopper was from very useful to extremely useful (grade 3 or higher) for the development of their designs, and; vi) $90 \%$ of students stated they intended to use Rhinoceros and Grasshopper in their next design opportunity. Among students' answers to the question "What aspects have parametric tools helped you with the most?" we find interesting to share, for instance: i) "parametric tools were able to take our rules and help generate a bi-product of them"; ii) "being able to adjust and reorder multiple objects at once rather than one by one"; iii) "allowed me to iterate [through] more designs", and "generating building forms based on existing design features or curved geometries like the stream edge or existing roads; iv) "creating custom grid patterns, selecting objects or areas of a field based on inputs like lists or predetermined dimension constraints." Figure 10 presents the charts with the survey results.

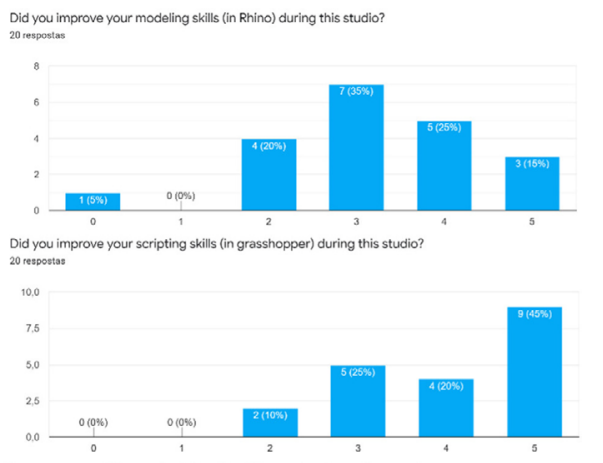

Please rate your skilltexpertise in handling Rhino - after the studio experience

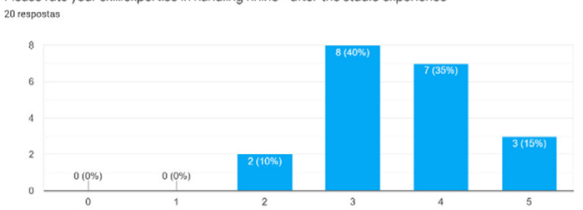

Please rate your skillexpertise in handling Grasshopper - after the studio experience 20 resosostas

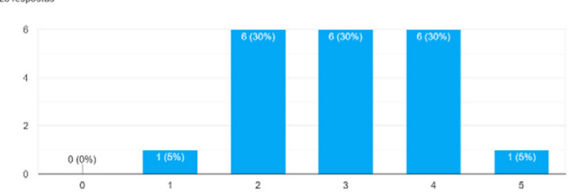

How useful were parametric tools (Grasshopper w. Rhino) for the development of your design?" "How useful were parametric tools (Grasshopper w. .. eloping multiple iterations of your design ideas? 20 respostse

15

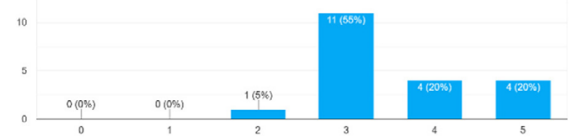

Would you consider using parametric tools (Rhino + Grasshopper) in a next design opportunit?

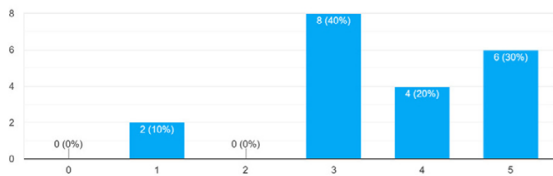

Figure 10: Results of the students' survey.

\section{DISCUSSION AND FINAL REMARKS}

The teaching experience focused on a teaching/learning computational approach that sought to enhance students' design processes by articulating shape grammars and parametric tools to improve students' abilities to address informal/low-income settlements design. This meant providing the students with new creative possibilities that allowed them to understand the relationship between cultural aspects and the built environment and, fundamentally, stimulating the exploration of the 
opportunities afforded by these new design media, with their potential and difficulties.

Therefore, computational design logic was a critical aspect of the teaching process. Most of the students considered that they increased their Grasshopper and Rhinoceros skills during the studio. Still, according to students, the course improved their abilities to understand and develop their ideas. In this sense, the students' answers reinforced our perception that the studio (and the teaching experience itself) contributed to increasing the students' abilities for dealing with urban design. Although a few students recognized some difficulty in assimilating software content (Rhinoceros and Grasshopper), their work resulted in exciting proposals for the intervention site due to the computational approaches they developed. Moreover, it is essential to highlight that this teaching approach demands time to learn and apply pattern languages, shape grammars, and parametric logics for urban design. It also requires some mathematical and programming skills to represent both algorithmically and visually the design solutions.

The Covid-19 pandemic caused some changes in the studio's planning since the meetings and the presentations had to be remote, which meant an extra challenge for all involved. However, we believe that two aspects were crucial for the results: first, a remarkable commitment to the studio tasks on behalf of students, and the fact that the first half of the course evolved face to face, which facilitated proceeding with the activities as planned when switching to online teaching.

Finally, we argue that it is crucial to use computational resources to design interventions in informal and lowincome contexts. Moreover, we believe that using computational approaches may be the key to solving complex design problems and, therefore, it is essential to include computational design studios in architectural and urban curricula. This studio can be seen as a step in this direction.

\section{ACKNOWLEDGMENTS}

The authors would like to thank all the students that attended the World studio 2020. This study was financed in part by the Coordenação de Aperfeiçoamento de Pessoal de Nível Superior - Brasil (CAPES) Finance Code 001 and by the Stuckeman Center for Design Computing (SCDC), Penn State University, USA.

\section{REFERENCES}

Alexander, C. Ishikawa S, Silverstein M. (1977). A Pattern Language: Towns, Buildings, Construction. New York, NY: Oxford University Press.

Beirão, J. (2012). CltyMaker / Designing Grammars for Urban Design. (Doctoral thesis, Delft University of Technology, Delft, The Netherlands). Retrieved from https://books.bk.tudelft.nl/index.php/press/catalog/series/ABE

Duarte, J. P. (2005). Towards the mass customization of housing: the grammar of Siza's houses at Malagueira. Environment and Planning B: Planning and Design, 32, 347-380. DOI:10.1068/b31124

Duarte, J. P., Rocha, J., Soares, G. (2007). Unveiling the structure of the Marrakech Medina: A shape grammar and an interpreter for generating urban form. Artificial Intelligence for
Engineering Design, Analysis and Manufacturing, 21(4), 317349

Duarte, J. P., Beirão, J. N. (2011). Towards a methodology for flexible urban design: designing with urban patterns and shape grammars. Environment and Planning B: Planning and Design, 38, 879-902. DOI:10.1068/b37026

Duarte, J. P., Beirão, J. N., Montenegro, N., Gil, J. (2012). City Induction: A Model for Formulating, Generating, and Evaluating Urban Designs. In: S. M. Arisona, G. Aschwanden, J. Halatsch, P. Wonka (Eds.), Digital Urban Modeling and Simulation. Communications in Computer and Information Science (pp. 73-98). Berlin: Springer.

Dogan, T., Yang, Y., Samaranayake, S., Saraf, S. (2020). Urbano: a tool to promote active mobility modeling and amenity analysis in urban design. Technology | Architecture + Design, 4(1), 92-105. DOI:10.1080/24751448.2020.1705716

Lima, F., Montenegro, N., Paraizo, R., Kós, J. (2017). Urbanmetrics: An Algorithmic-(Para)Metric Methodology for Analysis and Optimization of Urban Configurations. In: S. Geertman, A. Allan, C. Pettit, J. Stillwell (Eds.) Planning Support Science for Smarter Urban Futures. CUPUM 2017. Lecture Notes in Geoinformation and Cartography (pp. 47-64). Berlin: Springer.

Lima, F., Vallone, L., Costa, F., Rosa, A. (2019). (Para)metric evaluation of walkability, diversity and density in low-income neighborhoods. In Sousa, J. P., Xavier, J. P. and Castro Henriques, G. (Eds.), Architecture in the Age of the 4th Industrial Revolution - Proceedings of the 37th eCAADe and 23rd SIGraDi conference - Volume 3 (pp. 257-266). Porto, Portugal: University of Porto.

Lima, F., Costa, F. R., Rosa, A. (2020). Lógica algorítmicaparamétrica e urbanismo: uma revisão teórica e de modelos computacionais para projetos urbanos. Gestão e Tecnologia de Projetos, 15, 84-97. DOI:10.11606/gtp.162710

Mayall, K., Hall, G. B. (2005). Landscape grammar 1: spatial grammar theory and landscape planning. Environment and Planning B: Planning and Design, 32, 895-920

Nourian, P., Rezvani, S., Valeckaite, K. and Sariyildiz, S. (2018). Modeling walking and cycling accessibility and mobility: The effect of network configuration and occupancy on spatial dynamics of active mobility., Smart and Sustainable Built Environment, 7(1),101-116. DOI:10.1108/SASBE-10-20170058

Parish, Y. I. H., Müller, P. (2001). Procedural modeling of cities. Proceedings of the 28th Annual Conference on Computer Graphics and Interactive Techniques, 301-308. https://doi.org/10.1145/383259.383292

Steinø, N., Veirum, N. (2005) A Parametric Approach to Urban Design. In Digital design: the quest for new paradigms Proceedings of the 23rd eCAADe conference (679-686). Lisbon, Portugal: University of Lisbon

Stiny, G. (1980). Introduction to Shape and Shape Grammars. Environment and Planning B: Planning and Design, 7(3), 343351. https://doi.org/10.1068/b070343

United Nations. (2020). The Sustainable Development Goals Report 2020. Retrieved from http:// https://unstats.un.org/sdgs/report/2020/The-SustainableDevelopment-Goals-Report-2020.pdf

Verniz, D., Duarte, J. P. (2020). Santa Marta Urban Grammar: Unraveling the spontaneous occupation of Brazilian informal settlements. Environment and Planning B: Urban Analytics and City Science, $0(0), 1-18$.

Woodbury, R. (2010). Elements of parametric design. New York: Routledge.

World Bank. (2007). The Slum Networking Project in Ahmedabad: partnering for change (English). Water and Sanitation Program case study. Washington, DC: World Bank 